\title{
Representações, valores e crenças em discursos de professores da educação básica e implicações na (form)ação docente
}

\author{
Ev'Angela Batista Rodrigues de Barros*
}

\begin{abstract}
Resumo
Como importante política pública, o investimento na iniciação à docência, por meio de um programa específico - o PIBID - tem conquistado alguns resultados promissores na reaproximação entre futuros docentes e a escola pública. Na Universidade em que atuo, esse programa tem por princípio norteador ampliar a interlocução entre a academia e a educação básica, propiciando a todos os seus participantes momentos de estudo, discussão e enriquecimento pessoal, cultural e profissional, por meio das diversas atividades. Passando por momentos que vão desde a idealização, planejamento e execução dos projetos de intervenção, além da reflexão sobre os problemas enfrentados no cotidiano e ao retorno mais concertado à ação pedagógica, tem possibilitado emergir aspectos importantes relativos à docência, promovendo uma desautomatização de práticas e concepções pedagógicas, além de uma desnaturalização de procedimentos, permitindo refletir sobre o modo de enxergar a si e à realidade, tanto no âmbito profissional como mais amplamente. Como culminância, tem fomentado e possibilitado a participação dos envolvidos em seminários (internos e externos) com apresentação dos trabalhos realizados. Neste artigo, serão discutidas algumas representações sociais (MOSCOVICI, 2003), constitutivas do ethos da profissão docente, a partir dos discursos de cinco docentes da área de Letras, professoras do ensino médio da rede pública estadual. As respostas trazidas à discussão, a partir dos questionários aplicados, esboçam discurso(s) dos docentes sobre como se percebem e ao seu fazer pedagógico e delineiam-se sentidos e sentimentos atribuídos ao seu espaço de atuação, a escola básica.
\end{abstract}

Palavras-chave: Representações sociais. Discursos sobre a prática. Ethos.

\section{Introdução}

Neste artigo, será apresentada uma análise de representações sociais materializadas em discursos de alguns professores de Língua Portuguesa sobre si e sobre seu contexto de atuação, buscando compreender e interpretar tanto

\footnotetext{
" Pontifícia Universidade Católica de Minas Gerais (PUC Minas). Coordenadora de Gestão de Processos Institucionais do PIBID PUC Minas.
} 
os aspectos explicitados quanto silenciamentos que se fazem latentes. Serão focalizadas, sobretudo, crenças e (auto)percepções de profissionais atuantes na educação básica (ensino médio) em cinco diferentes instituições da rede pública de Minas Gerais, que atuam como coformadores dos graduandos de Letras do PIBID (Programa Institucional de Bolsas de Iniciação à Docência / CAPES). Trazer à tona alguns dos discursos que circulam na esfera escolar nos diz um pouco da perspectiva em que se colocam seus enunciadores.

Um dos grandes problemas da sociedade contemporânea, do ponto de vista do educador espanhol Jorge Larrosa, é que há uma série de fatores que fazem com que muitas coisas se passem, aconteçam, mas estas não constituem experiências reais para os sujeitos com que ocorrem. Basicamente, esse "entorpecimento" é provocado pelo excesso de informação (somos estimulados a buscar saber mais, porém nem sempre isso implica que algo significativo se tenha dado a partir dessa aquisição de informações ou conhecimentos) e pelo excesso de opinião (somos instados a, como sujeitos modernos e informados, opinar - de forma supostamente individual, pessoal e própria, de forma supostamente crítica, sobre tudo o que passa) - não ter uma opinião sobre algo é considerado uma lacuna insuportável. Dessa forma, “a opinião, como a informação, converteu-se em um imperativo. Em nossa arrogância, passamos a vida opinando sobre qualquer coisa sobre que nos sentimos informados" (LARROSA, 2002, p.22).

Ainda, Larrosa atribui a ausência de experiências ao fato de vivermos premidos pela falta de tempo: tudo passa demasiadamente rápido e de forma fugaz, o que, juntamente com a obsessão pelo novo, impede a conexão significativa entre os acontecimentos. Por fim, o excesso de trabalho: no afã de fazer simultaneamente muitas coisas e de mudar outras tantas, não conseguimos nos aprofundar em algo o tempo necessário para que se constitua verdadeiramente em experiência. Assim, sem nos apropriarmos verdadeiramente das dimensões daquilo que nos acontece; contentamo-nos, muitas vezes, em repetir discursos e gestos, de forma acrítica.

Se, por um lado, não ter o que dizer denota fragilidade e insegurança, por outro dizer algo sabidamente repetido, já dito, provoca desinteresse da audiência. Portanto, cobra-se que haja um discurso e que este seja autêntico, a despeito de nem sempre haver o tempo necessário para a reflexão e a gestação desse discurso.

Esse cenário de cobranças variadas - de qualificação continuada, de experiências significativas, de inovações metodológicas, de utilização de novas tecnologias (mas nem sempre disponíveis em quantidade e qualidade), etc. 
- é bastante familiar ao universo dos docentes brasileiros da educação básica, sobretudo os da rede pública. Tendo perdido o status econômico (dada a precarização salarial da carreira a partir da segunda metade do século XX) e social (perda do prestígio antes conferido aos mestres, por uma conjunção de fatores que aqui não cabe discutir ${ }^{1}$ ), os professores, em sua maioria, têm evidenciado um discurso de descontentamento e desmotivação em relação ao que fazem.

A maior parte desses docentes trabalha dois ou três turnos e tem pouco tempo destinado à formação continuada, à reflexão sobre sua prática, ao registro de suas "narrativas" - sejam as pessoais, sejam as profissionais -, o que os leva, frequentemente, a serem repetidores de ideias consensuais - tanto do âmbito da vida pessoal quanto da profissional -, conceituações embasadas em crenças ou informações parciais, obtidas de forma fragmentária. Esse cenário complexo, de dificuldades tão amplamente divulgadas, mas em que a busca de soluções por vezes para nos discursos oficiais, reflete-se na queda da procura pelos cursos de licenciatura em todo o País e na carência já instalada de profissionais em algumas áreas do magistério.

Neste artigo, apresentam-se discursos de cinco professoras da rede estadual de Minas Gerais, que lidam com o ensino médio. Selecionadas para atuar como coformadoras de graduandos que estão em processo de formação inicial, uma primeira mudança se observa na inserção destes nas escolas: não há o discurso da queixa e do desestímulo aos futuros docentes, o que é corriqueiro quando se trata da relação professor tutor/estagiário de licenciatura ("você é tão jovem, tem tempo para desistir do magistério e buscar outra carreira"), por outro lado ressoam outras queixas, outras perspectivas (ou falta delas). Assim, é relevante apreender de que forma o agir no discurso de tais docentes os aproxima e/ou os distancia dos licenciandos que têm sob sua supervisão.

A leitura/escuta atenta dessa polifonia de vozes e registros que nos chegam continuamente, estando à frente da coordenação de um grupo de cerca de 300 graduandos e 50 professores supervisores, evidencia que tem havido persistente

1 Soares (2002) faz uma retrospectiva da inserção da disciplina Língua Portuguesa no currículo e evidencia que, a partir dos anos 1950, com a crescente demanda de expansão de vagas nas escolas, acentuou-se a distância entre a escola pública para a classe média e para as classes populares; com o recrutamento pouco seletivo dos profissionais, houve crescente dependência destes em relação aos manuais didáticos, entregues com respostas já previstas, relegando ao(s) autor(es) o papel de pensar e ao docente o papel de cumprir tarefas. Na sequência, isso gerou certa desobrigação destes em relação à pesquisa de melhores métodos e ferramentas didáticas, quer por desinteresse, quer por falta de condições adequadas de inserção profissional. 
processo de "maturação pedagógica", em que os professores supervisores e os graduandos vão se conscientizando do próprio protagonismo e do desenvolvimento de competências relevantes, como aprender a dimensionar criticamente as práticas pedagógicas realizadas.

Este artigo se organiza da seguinte forma: na próxima seção, apresento o quadro teórico que deu suporte à pesquisa ora apresentada; em seguida, são explicitados os discursos (os dados) e a análise realizada, respaldada por breve exposição de vozes que se dizem a partir de uma experiência inovadora de ensino, que operou positivamente na construção da autoimagem dos envolvidos, bem como engendrou a crença em novas perspectivas docentes; finalmente, trago algumas considerações e desdobramentos possíveis a partir do cenário explicitado.

\section{A Teoria das Representações Sociais}

As Representações Sociais (RS) constituem sistemas de valores, ideias e práticas que permitem o estabelecimento de uma ordem necessária aos indivíduos a fim de se orientarem em seu mundo social, permitindo abarcar suas relações e atribuir sentidos aos objetos e eventos do cotidiano. Promovem a facilitação da comunicação entre membros de uma comunidade por dotá-los de um código para nomearem e categorizarem os vários aspectos de seu mundo e suas histórias individuais e grupais.

Para distinguir as representações dos mitos, das crenças religiosas e outras formas de abordagem da realidade, Moscovici (2003) parte do pressuposto de que não há separação entre o universo externo e o interno, pois, ao representar a realidade, o sujeito não o assimila passivamente, mas o reconstrói e esse processo é constitutivo desse individuo, permitindo-lhe situar-se no contexto social e material em que se inscreve. Dessa forma, as RS não são apenas "opiniões sobre" ou "imagens de", mas teorias compreensivas sobre o real, sistemas que têm uma lógica e uma linguagem particulares, uma estrutura de implicações baseada em valores e conceitos, e que "determinam o campo das comunicações possíveis, dos valores ou das ideias compartilhadas pelos grupos e regem, subsequentemente, as condutas desejáveis ou admitidas". (MOSCOVICI, 2003, p. 51).

Sendo assim, as RS significam os comportamentos cotidianos, por meio de dois processos, segundo Moscovici (op. cit.): a objetivação e a ancoragem. A objetivação dá realidade material a um objeto abstrato, fortalecendo o aspecto 
icônico de uma ideia imprecisa, o que se associa a um conceito de imagem. Num segundo momento, ocorre uma naturalização desse objeto, atuando no sentido da construção social da realidade. Pela ancoragem, o objeto é classificado entre as redes de categorização da sociedade, adequado à hierarquia existente das normas e valores sociais (cf. FLATH; MOSCOVICI, 1983). Assim, na formação de uma RS são cruciais aspectos como o modo de acesso à informação, o grau de injunção e/ ou de necessidade com que ela chega a essas pessoas, entre outros aspectos:

A quantidade e a forma das informações sobre o objeto, assim como o meio pelos quais elas se tornam acessíveis para o sujeito, o grau de interesse intrínseco ou externo que o objeto desperta e a necessidade mais ou menos premente de seu conhecimento para o grupo são variáveis que certamente afetarão - e por isso poderão explicar, pelo menos parcialmente - o conteúdo e a estrutura da representação. (SÁ, 1998. p. 71-72).

Isso implica que, para se entender as diferentes RS em jogo num determinado contexto social, é necessário remeter os indivíduos a sua contextualização, isto é, às condições sociais que geram e sustentam tais representações, às instituições e comunidades pelas quais eles transitam, à focalização das pessoas representativas de valores (ícones em relação aos quais estes indivíduos se remetem), além dos discursos que são construídos por eles ou dos quais são os destinatários - quem fala algo a tais indivíduos? Como? Qual o tom - ou de outra forma, os tipos de discursos (questões? injunções?). Há relação dialógica, que implique enunciação/ réplica? Ou a relação discursiva é assimétrica?

Em consonância com o explicitado por Larrosa, Alves-Mazzotti (2008), sob o escopo da Teoria das Representações Sociais (TRS), afirma que a sociedade contemporânea gera muitas situações em que somos instados, diante da grande "massa de informações", a opinar, nos posicionar, de forma "autêntica":

As novas questões e os eventos que surgem no horizonte social frequentemente exigem, por nos afetarem de alguma maneira, que busquemos compreendê-los, aproximando-os daquilo que já conhecemos, usando palavras que fazem parte de nosso repertório. Nas conversações diárias, em casa, no trabalho, com os amigos, somos instados a nos manifestar sobre eles procurando explicações, fazendo julgamentos e tomando posições. Estas interações sociais vão criando "universos consensuais" no âmbito dos quais as novas representações vão sendo produzidas e comunicadas, passando a fazer parte desse universo não mais como simples opiniões, 
mas como verdadeiras "teorias" do senso comum, construções esquemáticas que visam dar conta da complexidade do objeto, facilitar a comunicação e orientar condutas. Essas "teorias" ajudam a forjar a identidade grupal e o sentimento de pertencimento do indivíduo ao grupo. (ALVES-MAZZOTTI, 2008, p. 21, grifos meus).

Também no universo escolar, coexistem dois tipos de pensamentos - aqueles que Moscovici (2003) denomina "reificados" (ou acadêmico-científicos) e os "consensuais" (do senso comum ou experienciais). Os primeiros, mais valorizados, caracterizam-se pela busca de comprovação cientifica, por meio de rigorosos procedimentos lógicos e metodológicos, buscam abrangência e fidedignidade, e normalmente resultam em estratificação (ou especialização). Diferentemente, os saberes consensuais visam a uma legitimação de conhecimentos por meio de atividade compartilhada socialmente, calcada numa atuação cotidiana, coletiva; não há preocupação com exigências de objetividade e validação científica, mas a validação decorre da aceitabilidade pelo grupo. São estas produções intelectuais de cunho mais pragmático que formam as RS, por meio das quais as pessoas passarão a interpretar seus relacionamentos e nas quais basearão seus comportamentos e crenças sociais.

Para tentar desvendar as representações sociais (RS) presentes nos discursos produzidos, interpretar e atribuir significações a fatos percebidos/ relatados e a discursos socialmente constituídos, percebendo valores, opiniões, crenças, ideias dos participantes de um grupo, a partir do que espontaneamente revelaram em seus discursos escritos, três hipóteses se destacam: a) todos os componentes de determinado grupo tendem a ver/analisar/interpretar o mundo de forma semelhante, através de representações cristalizadas em razão do uso convencional; b) as RS possuem as funções de convencionalizar objetos, pessoas ou acontecimentos (dando-lhes forma, modelando ou categorizando, e isso é partilhado por um coletivo de pessoas), e de impor uma força irresistível sobre todos, prescrevendo o que percebemos ou imaginamos; c) as RS ocupam um lugar na sociedade pensante (por exemplo, influenciam na criação e circulação de metáforas com que as pessoas tendem a categorizar os objetos com que lidam, os fatos que presenciam, as experiências que vivenciam) e interferem no sentimento de pertença a determinado grupo.

A ambiência escolar é espaço educativo - físico e simbólico - de formação das novas gerações e de autoformação dos agentes que neste espaço circulam. Maturana 
(1998) postula que educar se constitui em processo no qual "a criança ou o adulto convive com o outro e, ao conviver com o outro, se transforma espontaneamente, de maneira que seu modo de viver se faz progressivamente mais congruente com o do outro no espaço da convivência." (MATURANA, 1998, p. 29 apud ASSIS; LOPES, 2009, p. 75). Pode-se acrescentar que a transformação nem sempre se dá de forma espontânea, mas certamente de forma gradual e mediada pelos contatos, pelas redes de relacionamentos valorizadas nesse processo.

A relação educativa coloca em contato sujeitos diferentes, com experiências e bagagens distintas. Inicialmente, isso não chega a ser tão problemático, posto que a criança vê em seu(sua) professor(a) alguém a ser imitado, reconhecido e valorizado. Essa relação especular dura, aproximadamente, até o segundo ciclo de idade de formação, por volta dos 10 anos. A partir daí, como forma de autoafirmação, o pré-adolescente não raro estabelece uma relação de antagonismo e as crenças, valores, representações do adulto-referência (professor, pais, etc.) já não servem; constituem-se novos grupos de referência (os amigos, artistas que se destacam na mídia, sobretudo os mais jovens, etc.) e são essas novas crenças e valores que passarão a balizar as condutas dos adolescentes por um bom período.

Essa constituição dinâmica do nosso sistema de crenças e valores - que precisa ser suficientemente sólido para lastrear nossas condutas e, ao mesmo tempo, suficientemente flexível para nos permitir novas aprendizagens (aprendemos melhor a partir daquilo que já conhecemos, reiteram as teorias sociocognitivas) e a ampliação da visão de mundo tornam compreensível que

as representações, que recobrem crenças, conhecimentos e opiniões partilhadas pelos indivíduos de um mesmo grupo, com relação a um dado objeto social, constituem para nós um tipo de realidade que pode sempre se alterar, já que a plasticidade é traço forte desse fenômeno. (ASSIS; LOPES, 2009, p. 75).

Embora no universo da escola, marcado pela desigualdade e hierarquização, os papéis sociais sejam diferentes porque os membros são desiguais, uma crença é que cada um tenha uma competência designada pelo conhecimento, pela diferença, pela função social. A despeito disso, as RS, compartilhadas, restauram e constituem uma consciência coletiva, pois integram o universo consensual e têm função de tornar familiar aquilo que não o seja, promovendo a adesão de cada indivíduo. 
No caso em discussão neste artigo, com base no mapeamento de representações a partir do discurso de professores já experientes, pode-se perceber como se dá a relação em que se constituem tanto o enunciador quanto o enunciatário, no caso, os bolsistas ID (iniciação à docência), visto que ambos atuam uns sobre os outros e se influenciam mutuamente. Essa análise nos permite detectar nuances do ethos do professor da escola básica, a partir do que deixam entrever em sua fala.

Entende-se ethos aqui sob a perspectiva de Amossy (2011), que afirma: “[...] deliberadamente ou não, o locutor efetua em seu discurso uma apresentação de si." (AMOSSY, 2011, p. 9). Ethos é uma imagem de si construída no e pelo discurso, às vezes enunciada com aspecto de cristalização de discursos (em que se intercruzam diversas vozes) que desencadeiam certos efeitos sobre opiniões e atitudes. Dessa forma, o locutor apresenta-se de acordo com o que ele acredita ser valorizado pelo público-alvo, elabora seu discurso a fim de confirmar/modificar seu "ethos prévio", isto é, evidencia uma concepção que considera apropriada de si e de tudo aquilo que faz com que ele seja quem é.

Desse modo, as crenças dos docentes interferem de forma inegável na prática que desempenham, nos resultados que buscam, na motivação que têm para se capacitar ou mesmo para continuar na carreira. Sabemos que as crenças atuam como um

filtro pelo qual passa todo e qualquer conhecimento e como algo que não está disponível de forma sistematizada para todas as pessoas, como está o conhecimento, mas existe a dimensão individual como a social e pode ser questionado e rejeitado por outras pessoas que não compartilham do mesmo sistema de crenças.[...] a crença não deixa instantaneamente de ser verdadeira para o individuo que a possui, mas se modifica na medida em que novas crenças são incorporadas no sistema de crenças de um indivíduo e essas novas crenças podem vir a substituir a anterior ou não" (LIMA, 2005 apud BRANDÃO, 2014, p. 25).

Disso decorre a relevância de, na vivência de suas práticas, cada agente, que assume múltiplos papéis sociais, ser instado a revelar-se enunciativamente nas distintas posições discursivas em que se inscrever. 


\section{Análise dos discursos produzidos: cenários da docência na educação básica a partir de algumas representações dos atores nela envolvidos}

O terreno da educação é campo fértil de geração de discursos e contradiscursos, de cristalização de certas representações e, em decorrência, de certas posturas metodológicas. Nesse sentido, Alves-Mazzotti (2008), em artigo sobre o impacto das representações sociais no âmbito da educação, fala do efeito deletério que tem a baixa representação dos professores sobre as crianças e jovens provenientes de famílias de baixo extrato socioeconômico: por trabalharem com baixas expectativas, gera-se um círculo vicioso que tanto engendra quanto justifica o fracasso escolar, pois se reforça a baixa autoestima de todos os atores, o que se traduz numa certa "desresponsabilização" dos docentes quanto ao grau de crescimento de seus alunos. Nesse cenário, a autora afirma que há

a necessidade de se ultrapassar o nivel da constatação sobre o que se passa "na cabeça" dos indivíduos, para procurar compreender como e porque essas percepções, atribuições, atitudes e expectativas são construídas e mantidas, recorrendo aos sistemas de significação socialmente enraizados e partilhados que as orientam e justificam. A intenção propalada de propiciar mudanças através da educação exige que se compreendam os processos simbólicos que ocorrem na interação educativa, e esta não ocorre num vazio social (ALVESMAZZOTTI, 2008, p. 20, grifos meus).

A fim de lançar luzes sobre parte desse universo da relação entre professor supervisor e graduandos (formação inicial), trazem-se e se discutem algumas vozes de professoras da escola básica que têm compartilhado com a universidade a tarefa de formação dos jovens docentes.

Em questionário encaminhado aos professores da área de Letras que já participaram do PIBID, foi obtida resposta de cinco (num total de sete docentes -6 professoras e 1 professor - que já exerceram e/ou ainda exercem este papel). Por limitações de tempo e espaço, não serão discutidas todas as respostas e suas nuances, mas alguns aspectos que nos permitem compreender melhor a ação desse importante ator. É necessário, também, que se dê visibilidade à voz dos licenciandos, mapeando como se sentem integrando esse processo de formação tutelada por um professor 
experiente na escola básica e por um coordenador de área, na Universidade. ${ }^{2}$

No caso em tela, foram trazidas à discussão algumas respostas que nos ajudam a compreender certas RS no âmbito da relação entre os professores supervisores e os graduandos sob sua orientação, bem como a visão que têm sobre os papéis que ora desempenham (professoras de ensino médio; coformadoras de licenciandos da Universidade; profissionais em formação continuada).

A análise que aqui se evidenciará levará em consideração dois eixos teóricos relevantes: as representações como "estruturas dinâmicas, operando em um conjunto de relações e de comportamentos que surgem e desaparecem" (cf. MOSCOVICI, 2003, p. 47) e a estereotipagem, como "operação que consiste em pensar o real por meio de uma representação cultural preexistente, um esquema coletivo cristalizado" (cf. AMOSSY, 2011, p. 125), o que nos permite identificar o ethos desse subgrupo da categoria "docentes da educação básica - anos finais do ensino fundamental e ensino médio - da rede pública de MG”.

\section{Alguns significados que emergem da voz dos professores supervisores do PIBID}

Os bolsistas ID começaram sua atuação nas escolas públicas com a incumbência de tentar delimitar respostas a questões cruciais, a saber: como e por que ensinar tal disciplina? O aluno está motivado a aprender? E o professor, está motivado a ensinar? Qual a importância do que é ensinado/aprendido em sala de aula no cotidiano? Como avaliar de forma adequada sem emprestar a esse momento o caráter de "pressão" que é gerado pelas tradicionais provas? Essas questões, entre outras, têm norteado o olhar lançado sobre a escola e também sobre todos os sujeitos envolvidos, compreendendo suas circunstâncias e singularidades, apre(e)ndendo sentidos por meio dos discursos explicitados, mas, também, do que fica nas entrelinhas, nos silêncios e engasgos do cotidiano.

Bakhtin (2003) afirma que "a língua penetra na vida através dos enunciados concretos que a realizam, e é também através dos enunciados concretos que a vida penetra na língua" (BAKHTIN, 2003, p. 282). Dar significado a essa teia de sentidos, compreendê-la, torná-la inteligível é algo a ser conquistado como

2 Esse projeto de análise do impacto do PIBID na formação dos licenciandos encontra-se em andamento sob o título "Percursos Formativos de Estudantes de Participantes do PIBID em IES Mineiras: Saberes, Práticas e Contextos de Formação" $(\mathrm{CNPq})$, projeto interinstitucional coordenado pela prof. ${ }^{a}$ Dr. ${ }^{a}$ Lorene dos Santos (PUC Minas), e conta com a participação de coordenadores de cinco IES - PUC Minas, UFSJ, UEMG, UFMG e UNIFAL. 
demanda para uma formação do docente como profissional e como cidadão.

Para Nóvoa (1992), a profissão docente precisa se enxergar melhor (se avaliar) e se dizer. Atualmente, nas escolas públicas, muitas vozes, antes emudecidas, passaram a "se dizer", a falar de anseios e trajetórias, da visão da escola e demais atores nela atuantes. Ainda, ele ressalta que há muito da pessoa no profissional e vice-versa. Isso é algo que se constata, cotidianamente, a uma simples observação das inter-relações professor/aluno, professor/pares, professor/direção. Não raro, são características pessoais que não deviam ser tão prevalentes (como a intransigência) a fonte de inúmeros conflitos que surgem no âmbito da escola. Considerando que as situações e os objetos não têm um significado a priori, porém o adquirem na relação com o outro, a realidade, etc., é nesta mesma relação que se podem compreender os sentidos do que afirmam os entrevistados (e até do que silenciam, às vezes dando respostas curtas e reticentes).

Por isso, os professores-supervisores foram questionados: "O que significa, para você, 'ser professor(a) de Língua Portuguesa' na educação básica?”. As respostas assumem um interessante espectro que perpassa a questão das diferentes infâncias e juventudes, com suas especificidades (apego excessivo à tecnologia e ao imediatismo, etc.), as dificuldades impostas pelo sistema de ensino até a grande responsabilidade de que se veem imbuídas, a despeito desse cenário desfavorável:

"Hoje, ser professora de Língua Portuguesa na educação básica é um grande desafio, pois os nossos alunos não querem saber de ler e muito menos escrever. Além de nos depararmos com o sistema educacional de ensino, que está cada dia pior e as condições precárias de serviço, ainda temos que saber lidar com a grande desmotivação dos alunos em adquirir o conhecimento." (professora A)

"Uma tarefa muito difícil nos dias atuais, principalmente em escola públicas. Os desafios são muitos, trabalhar conceitos que muitas vezes exigem pré-requisitos que os alunos não possuem; lidar com novas tecnologias sem a escola possui-las, e ter sempre em mente que é a formação básica, por isso deve ter o mínimo de falhas para não comprometer a formação integral dos alunos.” (professora B)

"Eu sinto uma grande responsabilidade. A defasagem de conhecimento é grande e as condições de trabalho são péssimas. É preciso exercer a profissão com espírito de teimosia e militância..." (professora C) 
"Ser professora de língua portuguesa significa ensinar a pensar, ensinar a sentir. Como diz Galeano ensinar a ser um sentipensador. Isso se dá pela leitura de textos variados mas principalmente pela literatura." (professora D)

"Ser professora de Língua Portuguesa na educação básica pra mim é importantíssimo. Sinto prazer em ensinar. Gosto de ensinar. Sinto realizada quando vejo que posso fazer diferença. Grande parte de meus alunos vem de famílias que não tiveram grande instrução e saber que ensiná-los pode trazer benefícios e produzir mudanças me alegra e provoca em mim orgulho, satisfação como profissional e pessoa." (professora E)

As respostas se construíram em torno do eixo temporal - "hoje"/“nos dias atuais"; essa temporalidade faz pressupor que já tenha sido menos desafiante, no entanto essa representação de um passado menos problemático não condiz com a realidade da profissão, que vem se precarizando ("o sistema de ensino cada dia pior") há pelo menos cinco décadas. Aparecem itens-chaves como "desafio" tanto em relação a aspectos psicossociais, como motivação e interesse, quanto à dimensão cognitiva (defasagem de conceitos/conhecimentos), "responsabilidade" (diante da tarefa a ser cumprida, da premência de não cometer falhas, mesmo diante das precariedades das condições de trabalho) e busca de realização (pessoal e profissional). A despeito das dificuldades, demonstram a crença de que podem "fazer a diferença", atuando com "espírito de teimosia e militância"; que seu trabalho pode "trazer benefícios" aos alunos "e produzir mudanças". Evidenciase, na fala de uma das professoras, a crença no poder transformador da leitura como forma de despertar o aluno, quando ela afirma que ensinar a pensar "se dá pela leitura de textos variados mas principalmente pela literatura”.

A representação que emerge do aluno é como alguém a ser despertado, a ser ensinado como pensar e sentir; alguém que não quer aquilo que deveria ("não querem saber de ler e muito menos escrever"); com defasagem de conteúdos, razão pela qual o professor enfrenta a dificuldade de ensinar "conceitos que muitas vezes exigem pré-requisitos que os alunos não possuem".

Cabem aqui dois comentários. O discurso do déficit cultural dos alunos de um estrato socioeconômico mais baixo vem sendo combatido nas escolas brasileiras há pelo menos 30 anos, no entanto continua se fazendo ouvir. Na lógica da transmissão de conteúdos, o encadeamento rígido e hierarquizado transforma 
em obstáculo o desconhecimento de certos conteúdos - ainda que os aprendizes tragam outros saberes em sua bagagem (o background conta pouco diante de um currículo estratificado). O fato de os alunos terem acesso a muitas informações e aparatos tecnológicos é ignorado ou subexplorado; o professor não dá conta de lidar com as novas TIC (tecnologias de informação e comunicação) de forma produtiva e sente-se impotente para lutar por alterações curriculares que tirem o peso de ter de ensinar conteúdos linearmente encadeados e obsoletos. Por fim, vale destacar que, como seres dotados de razão e volição, os alunos claramente pensam, sentem e expressam desejos, mas nem sempre o fazem da forma esperada pela escola. Por essa razão, tais demonstrações são desabonadas ou proscritas.

Não há, nas considerações acima, qualquer crítica aos professores - sua fala retrata algo já sabido: que a realidade na escola básica realmente é bastante tensa, desafiadora e complexa. Os docentes se sentem desautorizados por uma série de situações e confrontos, que lhes tiram o ânimo e o entusiasmo pela carreira. Sua fala, de modo geral, ressalta a representação social do grande ônus que lhes cabe: ressentem-se da situação de "abandono" dos estudantes por grande número de famílias (fica a encargo da escola o papel de ensinar e educar); do estresse decorrente do caráter instrumental da Língua Portuguesa para o sucesso nas demais disciplinas; da impossibilidade de contar com (e dominar) novas tecnologias que deveriam ser disponibilizadas pelas escolas, etc.

Nesse cenário, em que se ressentem de tantos dissabores, com o intuito de precisar um pouco mais de que modo a participação no Programa (em que assumiram o papel de coformadoras dos graduandos) vem impactando a sua formação continuada e a visão da carreira docente, foi-lhes questionado se conseguiam "estabelecer um paralelo em relação a sua atuação antes e depois da participação no PIBID”:

\footnotetext{
"Quando se trabalha tantos anos na área da educação, você muitas vezes se sente como os alunos, desmotivada a dar continuidade à profissão, que um dia você escolheu com tanto entusiasmo e paixão. O profissional acaba acomodando, não procura se reciclar, ou buscar novidades que poderão tornar suas aulas mais interessantes e prazerosas. Poder participar do PIBID trouxe para minha vida profissional uma nova esperança. À vontade de recomeçar, de reacender aquela chama que estava quase se apagando. Tive a oportunidade de voltar para a universidade, da qual saí em 1994, repleta de sonhos, projetos, vontade de ensinar e aprender cada vez mais.” (professora A)
} 
"É muito clara a diferença produzida pela participação no PIBID. O ânimo novo para o estudo, para a busca por novos meios, por novas perguntas e respostas, e, sobretudo as boas expectativas que nascem quando realizamos um trabalho com resultados." (professora B)

"Paralelo não. Sempre estive inserida na busca pelo conhecimento e envolvida em atividades de melhoria na educação de um modo geral. O PIBID veio somar aquilo que já fazia em termos de formação e participação em universidades. (grupo de pesquisa...). $\mathrm{O}$ novo para mim foi acompanhar alunas em processo de formação." (professora C)

"Não. Isso porque não creio que houve mudança alguma na minha prática, entretanto gostava das discussões dos debates, embora não me sentisse ouvida - no sentido de valorizada.” (professora D)

"Quando fui selecionada a fazer parte do PIBID havia feito 22 anos de Estado. Confesso que sentia necessidade de rever minhas práticas. Participar do PIBID revitalizou, melhorou minhas aulas. Trouxe novo ânimo." (professora E)

O principal aspecto apontado tangencia a questão da própria motivação para continuar na profissão, nela investindo tempo, esforços, etc. O fator "tempo de magistério", em vez de implicar maior vinculação e aprofundamento na relação com a profissão (segurança, realização, etc.), parece, nesse caso, gerar um entorpecimento que diminui a qualidade das ações. Com lentes opacas, ao olhar para seu fazer, os docentes não conseguem ser críticos em relação a suas práticas, sejam elas bem-sucedidas ou não.

Nesse sentido, o PIBID exerce relevante papel de valorização dos saberes docentes e de enraizamento do profissional na realidade da escola pública. Depois de destacar como o cotidiano acaba por deixar o profissional desmotivado, desinteressado por atualizar-se, uma das professoras salienta sua mudança nesse processo: "Poder participar do PIBID trouxe para minha vida profissional uma nova esperança". Da mesma forma, a professora B afirma que assumir esse papel de tutora dos graduandos resgatou-lhe "ânimo novo para o estudo, para a busca por novos meios, por novas perguntas e resposta" e lhe trouxe boas expectativas. Nessa mesma perspectiva, outra professora afirma que sua atuação como pibidiana reiterou o acerto de já participar de grupo de pesquisa na universidade, como forma 
de aperfeiçoamento profissional. ${ }^{3}$ Por fim, a docente E destaca a possibilidade de refletir e melhorar suas práticas pedagógicas: "Participar do PIBID revitalizou, melhorou minhas aulas."

De modo geral, a perspectiva a partir do ingresso no Programa foi de revitalização, de arejamento de práticas e concepções (sobretudo metodológicas, posto que os projetos são desenvolvidos com os bolsistas a partir de escolhas de temas, pesquisas sobre estes temas, produção de material, etc.).

Questionadas sobre o que percebem em relação à reação dos estudantes da educação básica, diante da presença dos pibidianos, responderam:

"Quando a equipe do PIBID chegou a nossa escola, inicialmente, os alunos ficaram receosos, quanto à participação dos bolsistas durante as aulas, ou nos projetos. Porém, com o passar do tempo eles começaram a se aproximar mais deles e a compreender, qual era a verdadeira função dos mesmos, dentro daquele ambiente escolar, que anteriormente era só dos alunos. Hoje, a parceria que existe entre alunos, bolsistas, funcionários e demais professores é muito grande, tanto no desenvolvimento dos projetos, como nas demais atividades escolares." (professora A)

"Percebo a diferença que o investimento no desejo faz. Os alunos se envolvem e sentem que a escola tem sim algo a dizer, que ela pode contribuir para a sua efetiva formação." (professora B)

"Os alunos/as acolheram de um modo geral o programa na escola e gostaram de participar das aulas e atividades de campo... Afirmaram verbalmente em avaliação que a intervenção pedagógica ajudou a melhorar a leitura e escrita. Alguns atribuíram o sucesso no vestibular e ENEM às aulas ministradas." (professora C)

"Não houve qualquer alteração." (professora D).

"Vejo que a participação do PIBID na escola mexe com a forma como os alunos lidam com a escola pública. Na verdade após este tempo do PIBID dentro do Brant, a presença dos pibidianos,

3 Alguns dos professores supervisores deixaram o PIBID por terem ingressado na pós-graduação stricto sensu - Mestrado - nas respectivas áreas. A rotatividade de supervisores tem sido bastante reduzida. Um caso que chamou a atenção da Coordenação foi o da professora $\mathrm{D}$, cujas falas na entrevista foram bastante negativas. Uma possível explicação para o fato de demonstrar sempre uma visão bem pessimista ("não houve mudança alguma" em sua prática, não se sentia ouvida e valorizada) reside no fato de ela ter tido que deixar o PIBID por razões administrativas - suas turmas se esvaziaram muito e foram fundidas, com isso a docente perdeu aulas e teve de sair da escola. Pelo tom de suas respostas, percebe-se a insatisfação que ficou, pois era uma agente bem engajada e repentinamente sua participação foi cerceada. 
a implantação dos projetos na escola tudo isto modificou o olhar de muitos alunos os quais passaram a valorizar mais a escola, as aulas sem contar na influência positiva na escolha de um curso de graduação. Agora mesmo fiquei super feliz ao encontrar no processo de seleção do PIBID, um ex-aluno, recém-formado, fazendo curso de matemática na PUC." (professora E)

De modo geral, os depoimentos apontam para uma interlocução produtiva entre os alunos do ensino médio e os graduandos. Além da identificação que sentem com os bolsistas ID (falam a mesma linguagem, a diferença etária às vezes é de 2 ou 3 anos, o que facilita a relação de confiança entre eles), a proximidade acaba por gerar o desejo de entrar numa universidade (e considerar que isso é possível).

Numa avaliação qualitativa, pois ainda estamos construindo indicadores precisos para apontar o impacto do PIBID nas escolas básicas, os docentes creditam uma melhora dos resultados dos alunos em avaliações sistêmicas (ENEM, Prova Brasil, etc.) à forma mais dinâmica de trabalho adotada (os trabalhos por projetos).

Se observarmos, percentualmente os posicionamentos das professoras, uma delas (o que equivale a $20 \%$ ) afirma não ter notado qualquer diferença, no entanto 4 (o que corresponde a 80\%) apontam diversos aspectos em que a presença dos pibidianos trouxe ganhos à escola: a professora A destaca a parceria que se cria entre os estudantes do ensino médio e os pibidianos, bem como com o restante do corpo docente, mesmo os profissionais que não integram a equipe do PIIBID. A professora $\mathrm{B}$ destaca o quanto o investimento em projetos a partir do desejo dos alunos (não valiam nota e, às vezes eram realizados após o horário normal de aulas) trouxe engajamento e crescimento para todos os envolvidos; $\mathrm{C}$ ressalta aspectos qualitativos da intervenção realizada (maior segurança para fazer o ENEM a partir das oficinas de leitura e produção escrita - e os resultados positivos); por fim, E atesta que todo o processo de inserção dos bolsistas "modificou o olhar de muitos alunos, os quais passaram a valorizar mais a escola". Trata-se de uma resposta altamente positiva face ao problema indicado pelos docentes, previamente, quando falaram do desinteresse dos discentes como um grande desafio a ser vencido.

Ainda, foi-lhes questionado se, "quanto aos graduandos que ficaram sob sua supervisão, nota-se alguma mudança". A resposta positiva é quase unânime:

"Recebi cinco graduandos em março de 2013, quando iniciei no PIBID. No começo tanto eles como eu, nos sentíamos muito 
inseguros, pois não sabíamos bem o que deveríamos fazer. $\mathrm{O}$ projeto proposto no início do ano, às demais escolas, já estava em andamento. A coordenadora de área nos auxiliou muito, passandonos confiança, explicando detalhadamente como deveríamos desenvolver nossas atividades, na escola. Lembro-me que no mês de abril já estávamos totalmente integrados, repletos de empolgação, milhares de ideias e planos, para criarmos um projeto de área inovador, que pudesse marcar o nosso início, com chave de ouro. E acho que conseguimos alcançar os nossos objetivos, pois tivemos belíssimos trabalhos apresentados pelos alunos e percebemos como foi prazeroso receber aquele feedback, do que havíamos planejado." (professora A)

"Noto que aqueles que querem ser professores se sentem mais estimulados, pois o contato com os alunos, com o trabalho bem sucedido realizado, reforça a "coragem" para enfrentar a profissão." (professora B)

"Algumas alunas manifestaram contentamento e alegria de poder participar do projeto e se inserirem na escola pública. Algumas se assustaram com as condições de trabalho e as dificuldades da gestão escolar... No todo acho que a experiência foi válida. A última turma aprendeu mais a trabalhar em equipe e estreitaram os laços de afetos com a escola. Penso que para uma próxima etapa podemos aprimorar o processo de acompanhamento.” (professora C)

"E como havia muita resistência e alguns jogos de vaidade, não houve mudança alguma; queriam cumprir o momento de estar ali e terminar o curso seguindo seus interesses até porque vários deles não queriam dar aulas na educação básica.” (professora D)

"Entre os graduandos vejo que alguns realmente têm tendência para serem professores. Notei no segundo ano de participação do PIBID o quanto para alguns esta experiência fez com que crescessem como futuros professores tornando-os mais participativos, mais desenvoltos, por isso vejo o PIBID como um programa de grande importância para a inserção destes jovens na área da educação, pois estes trabalham, fazem parte efetiva dos projetos da escola e isto com certeza faz diferença. É lógico que entre eles há aqueles que parecem um pouco desinteressados, porém talvez quando formarem o interesse pela profissão aflore." (professora E)

O discurso das respondentes reforça um sentimento inicial de insegurança de ambas as partes que vai se diluindo com a convivência e a criação de vínculos (com a professora, com o grupo de colegas e de alunos da escola básica), que é superado pelo sentimento de integração e de realização de algo significativo. Mostra, também, a importância da criação de um sentimento de pertença ao 
grupo e do desejo de "fazer a diferença" na profissão. Outras falas aludem à percepção de que alguns bolsistas, com essa iniciação à docência, reforçam sua opção pela licenciatura, o que lhes dá "coragem" para "enfrentar" a profissão. Como discurso dissonante, a professora $\mathrm{D}$ alega não ter percebido alterações, mas apenas o cumprimento de um período de trabalho na escola, sem que os bolsistas se apropriassem do que realmente a docência significa.

Nota-se, usualmente, no discurso que circula nas escolas (e extrapola seus muros), ao tratar da profissão docente, a instauração e manutenção de um campo semântico: o do enfrentamento de grandes obstáculos, para cuja superação há que se ter coragem. Isso evidencia um dos traços preocupantes que vem se infiltrando nos discursos sobre o magistério: a representação de que se trata de profissão insalubre, perigosa, desgastante, além de economicamente desvalorizada, o que concorre para afastar, cada vez mais, possíveis candidatos a cursar as licenciaturas ou, em as cursando, ingressar na carreira do magistério.

Por outro lado, mas ainda a partir do discurso das dificuldades, a fala dessas professoras retrata situação comum Brasil afora: um conjunto de docentes engajados, porém, às vezes, frustrados diante de uma conjunção de fatores conjunturais, intra e extramuros.

Houve outras questões, relevantes como forma de mapeamento de novas práticas, em cujas respostas, por exemplo, relataram os inúmeros projetos já desenvolvidos no bojo do PIBID e destacaram seus impactos. Alguns deles são:

"O projeto que criamos tinha como objetivo, aliar a parte teórica com a prática e aproveitarmos a leitura dos dois clássicos, que eu já havia indicado aos alunos. Surgiu então a primeira proposta, que foi a criação de uma paródia musical, tendo como base o estudo feito sobre a escola romântica. As principais características, os autores e suas respectivas obras, as gerações românticas e etc. Já a segunda foi a confecção de um jogo de tabuleiro pedagógico, abordando os diversos aspectos literários, presentes nas obras "Lucíola" e "Senhora", bem como os filmes Moulin Rouge e Orgulho e Preconceito. As propostas foram apresentadas aos alunos pelos bolsistas, através de slides e já de início a aceitação foi unânime. $\mathrm{O}$ trabalho foi desenvolvido durante o primeiro semestre inteiro. Ao término tivemos a grata surpresa com o belíssimo resultado. Trabalhos que nos deixaram emocionadas, felizes, pois nunca poderíamos imaginar que os alunos iriam produzir com tanto ímpeto, amor, satisfação aquele nosso sonho, que acabou se tornando realidade. Foi uma experiência única. E espero poder continuar sentindo cada dia mais esta emoção.” (professora A) 
"O trabalho de 2011 - Projeto Memorial - teve um impacto maior sobre os alunos, porque são histórias deles e isso trouxe uma carga muito grande de sentimentos, consequentemente teve um significado muito grande para mim.” (professora B)

"Elaboramos dois projetos com eixo na leitura e escrita. No ano de 2012: O PROJETO DE LEITURA E REVISÃO DE GÊNEROS com foco no desenvolvimento de atividades de cidadania e relações interpessoais. No ano de 2013: PROJETO DE LITERATURA: O SABOR PELO SABER LITERÁRIO E ARTÍSTICO com foco interdisciplinar em artes. (..) Os dois projetos foram bons. $\mathrm{O}$ impacto maior está na possibilidade de sair da escola em trabalhos de campo. (...) Creio que as alunas do curso de letras e aluno/as do Ensino Médio aprenderam e aprimoraram seus conhecimentos mutuamente juntamente com a professora." (professora C)

"Dentre as práticas, o sarau, as paródias e a produção dos minicontos e gravação dos vídeos foram para mim as que tiveram maior impacto, pois movimentaram as turmas, animaram as aulas. A prática faz total diferença, sem contar que os alunos se sentem valorizados ao ver exposto o que foi produzido." (professora E)

As entrevistadas apontam que houve muitos acertos, e nota-se que o foco foi trabalhar leitura e escrita com base em projetos de Literatura, aliando o "saber e o sabor". Destacaram, entre outros aspectos: o valor de trabalhar a parte teórica com a prática; apresentar o projeto aos alunos, buscando sua adesão; a emoção de verificar o "belíssimo resultado", que trouxe felicidade a docentes e a alunos; o envolvimento dos alunos do ensino médio, que produziram "com ímpeto, amor, satisfação"; o aprimoramento de conhecimentos; o desenvolvimento de atividades de leitura e escrita, com foco em cidadania e relações interpessoais; a busca da interdisciplinaridade.

Como uma espécie de síntese, tomemos a revelação da professora de que isso foi a realização de um sonho, que a emocionou fortemente. Todas revelam que conseguir chegar a um resultado satisfatório de ensino e aprendizagem passa também pela sensibilização e pelo resgate de emoções. Noutras passagens de suas falas, não arroladas aqui, destacam que os dissensos e os desafios cotidianos foram superados por meio do trabalho coletivo desde a concepção até a avaliação de cada projeto. Dizem que isso fez resgatar um pouco do sabor do (processo de adquirir) saber, o que exigiu de todos um árduo exercício de diálogos e negociações, de escuta e argumentação, de aprender de fato a colocar-se no lugar do outro, a ser propositivo e, ao mesmo tempo, respeitoso diante de diferentes ritmos e em meio a distintas concepções de mundo, de educação e de relação pedagógica. 
Acima, a professora $\mathrm{B}$ alude a um trabalho significativo e prazeroso realizado com alunos do ensino médio. Destacando-o em relação a outros igualmente produtivos, foi possível avaliar como uma prática bem sucedida espraia efeitos positivos sobre o discurso e as práticas dos atores envolvidos.

Aliando sua fala às demais, fica patente que, quando se consegue vislumbrar novas perspectivas para tornar mais dinâmicas e atraentes as aulas, os alunos da educação básica correspondem à altura. Metodologias que promovam o enriquecimento curricular, por meio de projetos envolvendo gêneros discursivos (como crônicas, memorial, notícia e outros do domínio jornalístico), com recurso à arte (fotos, músicas, etc.), retextualização de obras literárias, projetos de pesquisas (exploratórias, bibliográficas e, se possível, com coleta e análise de dados empíricos) planejados e executados juntamente com os alunos, entre outros -, promoveram, em contrapartida, maior engajamento de professores e alunos, potencializando a obtenção de resultados satisfatórios.

Com algumas das experiências realizadas no PIBID da Universidade em que atuo, tanto professores quanto graduandos participantes frequentemente relatam estarem adquirindo segurança, desenvolvendo a própria autonomia e observando uma melhora em suas competências leitoras e de escrita.

Barros et al. (2013) avaliaram um projeto desenvolvido no âmbito da área de Língua Portuguesa do PIBID e, na reflexão sobre esse projeto, destacaram um intercruzamento de vozes que diziam do trabalho como uma forma de autoconhecimento, de metacognição sobre o fazer docente, conforme excertos abaixo. O primeiro relato é da professora supervisora do PIBID:

Discutidas as múltiplas possibilidades do ensino da Língua Portuguesa e os vários direcionamentos encontrados para efetiválas, a equipe do PIBID centrou o seu trabalho na produção de um Memorial, como possibilidade de os alunos refletirem sobre suas vivências e associá-las ao conteúdo que vinha sendo trabalhado, de produção textual, aliada à observação artística e familiarização com outras formas de expressão subjetiva. $\mathrm{O}$ gênero seria utilizado para que os alunos pudessem contar sobre pessoas, momentos e fatos que marcaram suas vidas e, a partir do conhecimento e seleção, ilustrar cada um de seus registros com obras de arte com que se identificassem ou na qual percebessem alguma identificação com o tema. A equipe da Letras encaminhou a atividade de forma que se pudesse contemplar a produção textual voltada para um universo temático pouco explorado dentro das escolas, a pessoalidade. Proposição por vezes arriscada, dado que 
a individualidade, amiúde, suscita algumas considerações difíceis de administrar. Assim sendo, conduziu-se o trabalho de forma que os próprios alunos pudessem sugerir os elementos que iriam compor seus textos, os assuntos sobre os quais eles decidiriam tratar. (BARROS et al., 2013, p. 9).

Como salienta Nóvoa (1992), é crucial ao professor poder/saber dizer-se de si, tanto na dimensão pessoal quanto profissional, explicitar o porquê e o para quê daquilo que faz, sem romantizar ou sem racionalizar de forma extremada aquilo que faz, porém dimensionando de forma consciente o impacto e as implicações do seu fazer. Da mesma forma, a voz da graduanda de Letras, professora em formação, integrante da equipe, reflete sobre a experiência e os ganhos a partir da vivência daquele processo:

$\mathrm{O}$ fato de todos os graduandos participantes estarem inseridos há bastante tempo no ambiente escolar, assim como professores e coordenadores do projeto, faz com que tenhamos conceitos e preconceitos formados e, na maioria das vezes, tão fossilizados que poderiam dificultar o diagnóstico que deveria ser feito. Era preciso que fôssemos alertados desse desprendimento do "conhecido", para conseguirmos enxergar realmente o "novo" ambiente que adentraríamos. Portanto, esse diagnóstico - levantamento da instituição no que se refere aos espaços, aos tempos e aos sujeitos - culminou no retrato do perfil da escola e nos deu pistas da instituição em que alunos e professores estavam inseridos e de qual era a demanda dos sujeitos ali presentes. (...) A intenção com o memorial era a escolha por um projeto que pudesse sair dos moldes tradicionais de ensino de Língua Portuguesa e que contribuísse para que os alunos conhecessem a si mesmos, enquanto indivíduos, e, dessa maneira, escrevessem e compartilhassem seus pensamentos, experiências e sentimentos. Objetivamos, com esse primeiro projeto, despertar nos alunos o desejo do autoconhecimento e de resgate das memórias, relacionando a produção textual ao conhecimento e também à ampliação do universo da arte. (BARROS et al., 2013, p. 5-6).

E, por fim, como representante da universidade, agência formadora, a voz da coordenadora da área de Letras:

A escola tradicional, firmemente calcada na separação entre intelecto e afetividade, peca por fazer crer que a cognição se dá num fluxo autônomo de pensamentos que se autogeram, dissociados das plenitudes e vicissitudes da vida. Sabemos que diferentes culturas 
produzem modos diversos de funcionamento psicossocial, mas a questão da afetividade independe de especificidades culturais. (...) Pode-se, igualmente, pressupor que, a cada estágio de desenvolvimento humano, compreende-se uma nova configuração desse ser social em formação, com base nas interações e ressignificações dadas aos eventos de que participa, até a construção, pelo indivíduo, de sua autonomia. Em suma, o desenvolvimento cognitivo tem como elemento mediador, entre indivíduo e o mundo exterior, a linguagem, a operação com signos linguísticos e o sistema de representações que substitui o real. Tal sistema de representações é construído socialmente: além do intercâmbio social, ele se presta à função de contribuir para a construção do pensamento, a partir da generalização das experiências em categorias conceituais, e se consubstancia em instrumento de organização do conhecimento e da própria consciência humana. Acreditamos que tais questões devem sempre permear as discussões pedagógicas, cotidianamente, visto que o conjunto das atitudes tomadas e atividades realizadas é o resultado da interligação de vários fatores e múltiplas determinações. (BARROS et al., 2013, p. 14).

Essa polifonia de vozes que se pensam e se dizem nos leva a perceber que, se, por um lado, a reiteração de experiências docentes frustrantes tem o efeito de banalizar o fazer docente, fazer calar sentimentos e reflexões sobre as práticas cotidianas de sala de aula, o investimento em projetos autorais, visando à autonomização dos participantes, por outro lado, tem o poder de resgatar o sentido da docência - como processo de conduzir a apropriação e externalização de saberes -, minimizando a aridez dos discursos e enriquecendo o processo de formação seja no âmbito dos professores (formados e em formação), seja no âmbito dos alunos da educação básica que se veem mais enxergados e atendidos em suas demandas.

\section{Novas vozes docentes: memorial de formação em construção}

Investindo nesse processo, tão bem-sucedido, de imersão do sujeito docente em si (visualizando concepções, crenças, processos formativos, etc.) foi proposto e aprovado um projeto de pesquisa, em que dois gêneros acadêmicos são abordados, trabalhados em termos de constituição, relevância, objetivos, etc. - o Memorial de Formação ( $1^{\circ}$ semestre/2015) e o Artigo Acadêmico ( $2^{\circ}$ semestre $\left./ 2015\right)$ - e produzidos pelos participantes - 30 (trinta) bolsistas ID (iniciação à docência) e 6 (seis) professores supervisores atuantes nos ensinos fundamental e médio, da área de Letras (Português e Inglês). Na primeira versão do Memorial (maio /2015), já se fazem ressoar importantes vozes, que trazem representações dos docentes sobre si, sua formação, sua atuação. 
Embora incipiente esse trabalho, por meio de alguns fragmentos da primeira versão, já se confirmam nuances das crenças e representações discutidas anteriormente:

"Aos poucos sem que percebesse eu me tornara "Professora", com gosto por ser, dedicada a sempre estudar e planejar aulas que fizessem com que meus alunos aprendessem a matéria. Continuei a trabalhar em Morro do Pilar durante mais alguns anos, lá tive a alegria de ver inúmeros alunos que formavam como meus alunos, iam para Belo Horizonte fazer faculdade e sempre que voltavam à cidade, procuravam-me para agradecer e dizer o quanto o que aprenderam em Português comigo havia os ajudado. E isto me enchia de orgulho, e olha que naquele tempo o salário já não era nem de longe aquele que me entusiasmou a começar a trabalhar como professora. Naquele tempo eu já havia realmente $\mathrm{m}$ e transformado em Professora e a magia de ensinar já fazia parte de mim." (professora E, supervisora do PIBID, Memorial de formação $-1^{\mathrm{a}}$ versão, maio/2015).

Curiosamente, percebem-se duas concepções de docência - "Professora" e "professora", a primeira recebendo conotação positiva (é Professora, com letra maiúscula), em oposição à segunda forma (com letra minúscula). Há uma representação positiva do ofício (a despeito das dificuldades também delineadas) - "Professora, com gosto por ser.", "alegria", a menção ao retorno recebido (em que se ressaltam outros aspectos que não apenas o salarial).

Mais adiante, a mesma professora diz:

"O trabalho com o PIBID apesar de naquele primeiro momento ter sido direcionado às turmas dos terceiros anos, ajudou-me com as turmas do PAV - Projeto "Acelerar para Vencer" - e também com o nono ano, pois em conversa com os pibidianos eu conseguia ver através do olhar deles soluções e/ou formas de enxergar aquelas situações como casos que havia ainda como serem trabalhados, o que às vezes na visão cansada e com pouca motivação do professor que está na sala de aula há muito tempo fica quase impossível perceber. Nas nossas reuniões, expunha acontecidos naquela turma e discutia o que fazer. E, muitas vezes, este "o que fazer" era além do planejado de aulas que visassem sanar as dificuldades encontradas, muitas vezes o necessário era trabalhar a imagem desse aluno, era trabalhar a estima da turma, e isto só consegui perceber através do olhar desses jovens que trabalhavam comigo no PIBID”. (Idem.) 
De relevante neste fragmento, nota-se a aprendizagem compartilhada (a troca de experiências e saberes), o estudo e a discussão para planejamento de metodologias mais atrativas (muitos dos pibidianos têm quase a mesma idade dos educandos do ensino médio, o que gera identificação e empatia), o reconhecimento da oposição "vista cansada" / olhar não opaco, inovador dos jovens. Tudo isso vem sendo considerado uma grande oportunidade de crescimento para todos os envolvidos.

Uma das professoras participantes do PIBID, num dos encontros da área, disse que "no PIBID a gente pode errar". Nota-se, por esta fala, a pressão que muitos dos professores sentem com relação a seu fazer; outra representação amplamente difundida é que o professor de escola pública “não está nem aí", o que, certamente, é uma generalização apressada, que não recobre o conjunto dos docentes. $\mathrm{O}$ grupo de professores coformadores dos pibidianos se mostra, em suas falas, bastante focado na melhoria da formação própria e dos bolsistas por elas tutelados.

Retomando o que discutimos teórica e empiricamente sobre as RS (representações sociais), verifica-se que são bastante dinâmicas as estruturas que permeiam os discursos, as relações e os comportamentos dos docentes aqui iluminados. Diversas falas nos remetem à estereotipagem de que se reveste a visão do magistério: ainda se nota um pouco da antiga representação de que o professor "ajuda" seus discípulos, abre-lhes caminhos; com seu fazer, o "mestre" ensina conteúdos que beneficiam aos "discípulos", auxiliando-os a conquistar seus objetivos. Essa visão romantizada faz parte, ainda, do ethos dos docentes da educação básica brasileira, embora muitos, atualmente, já evidenciem uma visão mais "profissional” do ofício.

\section{Considerações finais}

A atividade representativa constitui um processo que permite detectar de que forma se manifestam os discursos (assumidos como próprios, porém consolidados a partir de um intercruzamento de vozes sociais). A situação ou objeto representado pelo discurso deixa de existir em si mesmo e se converte numa relação com outras situações e objetos a que foi vinculado, a partir de escolhas (conscientes ou não) dos indivíduos, as quais são orientadas por experiências (cf. LARROSA; MOSCOVICI). Os vínculos que se estabelecem em torno do objeto traduzem necessariamente uma escolha, a qual é orientada por experiências e valores do sujeito (cf. ALVESMAZZOTTI, op. cit.). 
Notamos, por meio da análise dos dados, brevemente exposta aqui, que há o imbricamento daquilo que o sujeito é (ou diz ser) com aquilo que é por ele vivido, testemunhado e avaliado.

Os sentidos não são imutáveis, assim como as crenças e representações não se alteram de forma radical. Há uma transição, uma mesclagem de valores, em que interferem fatores como o crescimento/amadurecimento, a atuação profissional (em um lugar específico, com características específicas), a rede de relacionamentos, etc. Dessa forma, conhecer um pouco do que pensam os docentes é um indicador relevante para os que atuamos como formadores, pois nos permite repensar currículos e rumos da formação, seja na instituição acadêmica em si, seja no âmbito das ações do PIBID.

No presente, para muitos a participação no PIBID é uma forma de "revisitação" da própria história de ingresso no magistério, com a oportunidade de maior qualificação profissional, por meio do retorno à universidade e da presença desta no seio da escola básica, cenário em que tudo transcorre.

Ainda que indicadores e instrumentos sistematizados de avaliação dos impactos desse Programa encontrem-se em construção, por meio do contato cotidiano com os bolsistas, dos relatos e do que evidenciam em artigos (com que participam de eventos acadêmicos) ou outros, como o memorial (que vêm construindo no projeto de pesquisa em curso), algumas transformações e conquistas rumo à valorização do magistério e à perspectiva de permanência dos jovens licenciandos na profissão se fazem notar. O breve relato das reflexões a partir de um projeto de intervenção realizado nos mostra que é possível fazer algo necessário de outra forma, mais prazerosa, o que traz autoconfiança, eleva a autoestima e resgata a crença em novas possibilidades para uma carreira bastante desgastada atualmente.

A partir dos desafios e precariedades que emergem das falas das entrevistadas, percebe-se que são necessários investimentos urgentes na construção de um novo projeto de Educação, que deve partir da avaliação dos valores, crenças e representações que se contrapõem na ambiência escolar, da detecção de quais são os valores a serem sustentados, contra quais crenças vale a pena o embate, enfim, qual o projeto que se deseja alicerçar e construir - em termos filosóficos, políticos e pedagógicos.

Para manter na carreira os bons profissionais, reconquistar a confiança e renovar o interesse das novas gerações por este ofício, há longo caminho a percorrer, o qual inclui, necessariamente, um investimento maciço e sistemático na formação e na 
melhoria das condições de trabalho dos professores que atuam na educação básica, mas que passa também pela mudança na representação difundida - na mídia, nos discursos políticos sobre e para os professores. E certamente, isso inclui, ainda, priorização radical da educação nos investimentos públicos e uma compreensão de que os professores são peça-chave nesse processo.

\begin{abstract}
As an important public policy, investment in the initial teaching training, through a specific program - the PIBID - has gained some promising results in the rapprochement between future teachers and public school. At the University in which I work, the best guiding principle of the Program is to expand the dialogue between universities and basic education, enabling all the participants moments of study, discussion and personal, cultural and professional enrichment through various activities. Going through times ranging from ideation, planning and implementation of intervention projects, as well as the reflection on the problems faced in everyday life and more concerted return to pedagogical action, has allowed emerging important aspects related to teaching, promoting deautomatization of educational practices and beliefs, in addition to a denaturalization of proceedings, allowing perceive how to see yourself and the reality, in the professional scope and more widely. As a culmination, it has fostered and enabled the participation of involved in seminars (internal and external) with presentation of their papers. In this article we will discuss some social representations (cf. Moscovici, 2010), which constitute the ethos of the teaching profession, from the speeches of five teachers of Portuguese Language, all of them high school teachers at public schools. To Larrosa (2002), we are "living beings with words," and our lives are mediated by words. Thus, the answers brought to discussion, from questionnaires, sketches some speeches of teachers about how they perceive themselves and their pedagogical practice, and we can outline some senses and feelings attributed to their performative space, basic school.
\end{abstract}

Keywords: Social representations. Speeches about the practice. Ethos.

\title{
Referências
}

ALVES-MAZZOTTI, Alda Judith. Representações sociais: aspectos teóricos e aplicações à educação. Revista Múltiplas Leituras, v.1, n. 1, p. 18-43, jan./jun. 2008

ASSIS, Juliana Alves; LOPES, Maria Angela Paulino Teixeira. Ethos, discursos e representações na atividade de avaliação de textos escritos: pistas de um processo de formação de professores. Scripta, Belo Horizonte, v. 13, n. 24, p. 71-94, 1. sem. 2009. 
AMOSSY, Ruth (Org.). Imagens de si no discurso: a construção do ethos. São Paulo: Contexto, 2011.

BAKHTIN, Mikhail M. Estética da criação verbal. Tradução de Maria Ermantina Galvão G. Pereira. Martin Fontes: São Paulo, 1997. Disponível em: <http:// pt.scribd.com/doc/20786562/LIVRO-BAKHTIN-Estetica-Criacao-Verbal>.

BARROS, Ev'Angela Batista Rodrigues de; SOUZA, Girlene R.; ROCHA, Raiane Chaves da. Memorial e validação do saber da experiência: diferentes perspectivas sobre uma prática docente bem sucedida. In: CBE, 4., UNESP, 2013.

BARROS, Ev'Angela Batista Rodrigues de; SOUZA, Girlene R.; ROCHA, Raiane Chaves da. O gênero memorial e a validação do "saber da experiência": três perspectivas sobre uma prática docente bem sucedida. Revista do Instituto de Ciências Humanas. Disponível em: <http://periodicos.pucminas.br/index. $\mathrm{php} /$ revistaich/issue/ current>.

BRANDÃO, Giliard Dutra. Crenças sobre o Ensino de Português como Língua Estrangeira: Práticas Discursivas de Professores Formadores e em Formação Inicial. Dissertação (Mestrado) - CEFET-MG, Belo Horizonte, 2014.

LARROSA, Jorge Bondia. Notas sobre a experiência e o saber da experiência. Revista Brasileira de Educação, n. 19, p. 20-28, 2002.

MOSCOVICI, Serge. Representações sociais: investigações em psicologia social. Petrópolis: Vozes, 2003.

FLATH, Esther; MOSCOVICI, Serge. Social Representation. In: HARRÉ, Rom; LAMB, Roger (Ed.). The Dictionary of Personality and Social Psychology. Londres: Basil Blackwell Publisher, 1983.

SÁ, Celso Pereira de. A construção do objeto de pesquisa em representações sociais. Rio de Janeiro: EdUERJ,1998.

NÓVOA, António S. da. Os professores e as histórias da sua vida. In: Vidas de professores. Porto: Porto Editora, 1992. p. 11-30.

SOARES, Magda Becker. Português na escola - História de uma disciplina curricular. In: BAGNO, Marcos (Org.). Linguística da norma. São Paulo: Loyola, 2002.

Submetido em: 31 de maio de 2015. Aceito para publicação em: 02 de outubro de 2015. 
